\title{
Telavancin, a new lipoglycopeptide antimicrobial, in complicated skin and soft tissue infections
}

\author{
This article was published in the following Dove Press journal: \\ Infection and Drug Resistance \\ 8 March 201I \\ Number of times this article has been viewed
}

\author{
Lida Jafari Saraf' \\ Samuel Eric Wilson ${ }^{2}$ \\ 'Veterans Administration Medical \\ Center, Long Beach, CA, USA; \\ ${ }^{2}$ Department of Surgery, University \\ of California, Irvine, CA, USA
}

\begin{abstract}
Telavancin, a novel lipoglycopeptide with rapid concentration-dependent bactericidal effects, is a semisynthetic derivative of the glycopeptide, vancomycin. Telavancin has a dual mechanism of action, ie, inhibition of peptidoglycan polymerization and disruption of the bacterial membrane. It has linear pharmacokinetics, rapid bactericidal killing, and broad spectrum activity against Gram positive bacteria, including methicillin-resistant Staphylococcus aureus (MRSA) and vancomycin-resistant S. aureus. Phase II and III clinical trials for complicated skin and skin structure infections have shown telavancin to have similar efficacy and tolerability to that of vancomycin and standard anti-staphylococcal $\beta$-lactams plus vancomycin. In Phase II trials, there was a significant difference in eradication of MRSA between groups, ie, telavancin therapy $92 \%$ and standard therapy (vancomycin, nafcillin, oxacillin, or cloxacillin) $68 \%$ $(P<0.05)$. In Phase III trials, among clinically evaluable patients who had MRSA isolated at baseline, the overall therapeutic response was higher in patients treated with telavancin than in patients treated with vancomycin $(89.9 \%$ versus $84.7 \%$; $95 \%$ CI $-0.3,10.5)$. Also, the efficacy of telavancin was not inferior to that of vancomycin for the treatment of complicated skin and skin structure infections in the clinical trials.
\end{abstract}

Keywords: telavancin, methicillin-resistant Staphylococcus aureus, MRSA, complicated skin and skin structure infections, Gram-positive bacteria

\section{Introduction}

Staphylococcus is the leading cause of bacterial infections involving the blood stream, skin, and soft tissue. After worldwide use of penicillin, which was highly effective against Staphylococcus aureus during the 1940s, penicillin-resistant S. aureus was reported. Methicillin was introduced in 1959 to combat this penicillinase-producing bacterium, and beta-lactamase-resistant antibiotics, including methicillin, nafcillin, and the cephalosporins, were in common use by the late 1950s and early 1960s. By 1961, the first isolate of methicillin-resistant $S$. aureus (MRSA) had been identified, and it soon became a major cause of hospital-associated (nosocomial) infections. ${ }^{1}$ In the US, the mortality rate associated with invasive MRSA infections has been estimated at $20 \%$, and these infections are probably the leading cause of death by any single infectious agent in that country. ${ }^{1}$ Fatalities resulting from these infections are estimated to surpass those caused by human immunodeficiency virus/acquired immunodeficiency syndrome. ${ }^{1,2}$ MRSA is a global public health problem widely encountered in health care practices. ${ }^{3-6}$ Today MRSA is both a nosocomial and community-acquired isolate, accounting for more than $50 \%$ of $S$. aureus isolates in intensive care units in the US. ${ }^{7,8}$
Correspondence: Lida Jafari Saraf University of California, Irvine, 333 City Blvd, City Tower, Suite 810 West, 5375 Orange, CA 92868 , USA

$\mathrm{Tel}+\mathrm{I} 7 \mid 44567246$

Fax +I 7144568205

Email lida.jafarisaraf@va.gov 
S. aureus produces Panton-Valentine leucocidin, a toxin which is now an established virulence factor linked to community-acquired MRSA strains. ${ }^{9}$ Panton-Valentine leucocidin has been associated with specific human infections in skin and soft tissues. ${ }^{10}$ Infection with community-acquired MRSA is most commonly associated with skin and soft tissue infection, such as cellulitis, boils, and furuncles (abscesses) which, if untreated, may lead to osteomyelitis or necrotizing fasciitis. ${ }^{11,12}$ In addition, $S$. aureus toxins may result in toxic shock syndrome. ${ }^{13}$

Hospital-associated MRSA infection requires aggressive antimicrobial therapy, and is associated with increased mortality among hospitalized patients. ${ }^{14,15}$ Risk factors for nosocomial MRSA infection have been well established, and include dialysis, recent hospitalization or surgery, residence in a long-term care facility, prolonged antimicrobial therapy, and indwelling percutaneous medical devices or catheters. ${ }^{11}$ This paper reviews the published clinical data on the role of telavancin in the treatment of complicated skin and soft tissue infections.

\section{Description and mechanism of action}

Telavancin, a novel lipoglycopeptide with rapid concentrationdependent bactericidal effects, is a semisynthetic derivative of the glycopeptide, vancomycin. Telavancin has a lipophilic side chain (decylaminoethyl), as well as a negatively charged phosphonomethyl aminomethyl group. ${ }^{16,17}$ The lipophilic side chain has been hypothesized to increase the membraneanchoring properties of telavancin, leading to enhanced affinity for lipid II, a bacterial membrane-anchored cell wall precursor. Lipid II is essential for bacterial cell wall biosynthesis. The liposaccharide element inhibits transglycosylase enzymes, which are directly responsible for the production of immature peptidoglycan. Peptidoglycan is a polymer consisting of sugars and amino acids that form a mesh-like layer outside the plasma membrane of bacteria, forming the cell wall. The polar substituent (phosphonomethyl aminomethyl) appears on the resorcinol-like 4'-position of amino acid 7 of the telavancin structure, and this hydrophilic side chain is believed to increase distribution in the body and reduce potential nephrotoxicity by promoting rapid clearance. ${ }^{18-21}$

Telavancin possesses a unique dual mechanism of action. Like vancomycin, telavancin inhibits transglycosylate activity and bacterial cell wall synthesis by interfering with the polymerization and cross-linking of peptidoglycan, a process that involves binding to peptidoglycan precursors terminating in D-alanyl-D-alanine. ${ }^{22}$ Unlike vancomycin, telavancin also binds to the bacterial membrane, disrupting its functional integrity. This action is mediated by targeted interaction with the cell wall precursor, lipid II. Thus, telavancin has a dual mechanism of action, ie, inhibition of peptidoglycan polymerization and disruption of the bacterial membrane..$^{20-25}$

\section{Bactericidal effects}

Preclinical studies showed that telavancin has a more potent antimicrobial effect against methicillin-sensitive $S$. aureus (MSSA) and MRSA than do the beta-lactams, linezolid, and vancomycin. For example, in a neutropenic mouse thigh model of infection, telavancin was found to be four times more potent than vancomycin against MRSA and 43 times more potent than nafcillin against MSSA. This higher potency against both MRSA and MSSA was also documented in immunocompetent animal models. Peak and trough serum levels of telavancin achieved in the FAST 1 study were 264 and 16 times greater than the minimum inhibitory concentration (MIC) $)_{90}$ values, respectively, for both MSSA and MRSA strains. These findings extend to other resistant Gram-positive cocci and methicillin-resistant coagulase-negative Staphylococci. ${ }^{26-28}$

Telavancin exerts concentration-dependent bactericidal activity against Gram-positive organisms in vitro, including a wide range of clinical isolates that are resistant to other antibiotics. Telavancin affects bacterial plasma membrane function, including membrane potential depolarization, and increases permeability, and these actions are observed at higher but clinically achievable concentrations. This multifunctional mechanism of action accounts for the rapid bactericidal activity of telavancin, as well as its activity against bacterial strains with reduced susceptibility to vancomycin, such as glycopeptide-intermediate $S$. aureus, heterogenous glycopeptide-intermediate $S$. aureus, and vancomycinresistant $S$. aureus. ${ }^{12,16,22,26-28}$

Like other glycopeptide antibiotics, telavancin is also effective against Gram-positive anaerobes, including Clostridium, Lactobacillus, Propionibacterium, Peptostreptococcus, and Corynebacterium species at concentrations of $2 \mu \mathrm{g} / \mathrm{mL}$ or lower. In vitro studies have shown that telavancin is bactericidal against clinically important Gram-positive bacteria, including drug-resistant strains, such as MRSA, vancomycin-intermediate $S$. aureus, and penicillin-resistant pneumococci. ${ }^{25}$ 


\section{Pharmacokinetics}

The pharmacokinetic parameters of telavancin have been studied in mice, rats, dogs, and monkeys. Linear kinetics were seen in the telavancin half-life after prolonged dosing at 13 weeks in rats. The primary route of elimination for telavancin is renal. ${ }^{29}$ The long half-life (7-9 hours) and postantibiotic effect (4-6 hours) allows for once-daily intravenous administration. The drug is not available in oral form. ${ }^{26,27}$

Pharmacokinetic studies of telavancin were performed during Phase I clinical trials on healthy volunteers and selected subjects with renal or hepatic impairment. When infused intravenously over a period of 30-120 minutes, telavancin demonstrated linear pharmacokinetics within a dose range of $7.5-15 \mathrm{mg} / \mathrm{kg}$. Steady state of telavancin in blood was achieved by day 3 or 4 , with no evidence of tissue accumulation. Telavancin elimination is renal at a dose $\geq 5 \mathrm{mg} / \mathrm{kg}$, and its half-life is between 6.9-9.1 hours in healthy subjects. ${ }^{30}$

The recommended daily therapeutic dosage of telavancin is considered to be $10 \mathrm{mg} / \mathrm{kg} /$ day in patients with a creatinine clearance above $50 \mathrm{~mL} / \mathrm{min}$. The observed half-life of telavancin at this dosage was 7-9 hours. The plasma concentration of telavancin increases in a linear fashion proportional to dose, without any clinically important drug accumulation. ${ }^{30}$ These data further support the recommendation for oncedaily dosing.

For patients with a creatinine clearance of $30-50 \mathrm{~mL} / \mathrm{min}$, $75 \%$ of the dose $(7.5 \mathrm{mg} / \mathrm{kg})$ is recommended, while for patients whose creatinine clearance is less than $30 \mathrm{~mL} / \mathrm{min}$, an increased dosing interval up to 48 hours is recommended. ${ }^{31}$ Based on an in vitro model, telavancin is not recommended in patients with renal failure on hemodialysis. ${ }^{32}$ The pharmacokinetics of a single $10 \mathrm{mg} / \mathrm{kg}$ dose of telavancin in eight patients with significantly compromised liver function (Child-Pugh Class B) did not show any significant difference between normal subjects and patients with moderate hepatic impairment. ${ }^{33}$ Telavancin has a short distribution phase, followed by a decrease at a rate proportional to its initial serum concentration (monoexponential decline). Age 65 years and older did not affect telavancin clearance, but there was a more extensive volume of distribution and longer half-life. ${ }^{34}$

Serum peak and trough concentrations were measured in Phase II clinical trials. Patients older than 18 years were administered the study medication for at least 4-14 days. In the first trial, 48 patients receiving telavancin $7.5 \mathrm{mg} / \mathrm{kg}$ once daily had a mean peak of $66 \pm 12 \mu \mathrm{g} / \mathrm{mL}$ and a trough of $4 \pm 0.8 \mu \mathrm{g} / \mathrm{mL}$. In the second trial, 47 patients receiving telavancin $10 \mathrm{mg} / \mathrm{kg}$ once daily had a mean peak of $82.2 \pm 27.3 \mu \mathrm{g} / \mathrm{mL}$ and a trough of $8.66 \pm 7.28 \mu \mathrm{g} / \mathrm{mL}{ }^{26,27}$

In one study of tissue penetration by telavancin, nine healthy subjects aged $21-46$ years received telavancin $7.5 \mathrm{mg} /$ $\mathrm{kg}$ once daily for 3 days, and serum levels were evaluated on the third day. The steady-state area under the curve in blister fluid was $40 \%$ of its plasma concentration, ie, enough to eliminate pathogens ${ }^{35}$ In a study in 20 healthy subjects, telavancin showed good penetration into the epithelial lining fluid, yielding a fluid:plasma concentration ratio of 0.75 . The mean concentration of telavancin in epithelial lining fluid was 2-8fold higher than the $\mathrm{MIC}_{90}$ value. ${ }^{36,37}$ Levels of telavancin were observed to be higher in alveolar macrophages than in epithelial lining fluid, and were not affected by the presence of lung surfactant, which is an important consideration in the treatment of pneumonia. ${ }^{29,35-38}$ Telavancin showed $93 \%$ protein binding in human plasma compared with approximately $50 \%$ for vancomycin. Plasma protein had minimal impact on telavancin activity against staphylococci and streptococci. ${ }^{16}$

\section{Rationale for a new antistaphylococcal antimicrobial}

Vancomycin remains the standard treatment for serious MRSA infections, and is now the second most common antibiotic used in hospitals. In 50 years of use, only six clinical MRSA strains with vancomycin resistance have been identified, but there are several concerns about vancomycin, ie, heteroresistance in MRSA (small numbers of organisms have high vancomycin MICs), "MIC creep", which describes an increase in recent years in numbers of clinical isolates of both MRSA and MSSA with vancomycin MIC $\geq 2 \mu \mathrm{g} / \mathrm{mL}$ (strains now considered only immediately sensitive to vancomycin), and prolonged MRSA bacteremia in many patients despite adequate vancomycin treatment, as indicated by trough levels of $15-20 \mu \mathrm{g} / \mathrm{mL}$. The standard regimen of intravenous vancomycin is $1 \mathrm{~g}$ every 12 hours. In cases of vancomycin failure, the options are linezolid $600 \mathrm{mg}$ every 12 hours, daptomycin $6-8 \mathrm{mg} / \mathrm{kg} /$ day, clindamycin $600 \mathrm{mg}$ every eight hours, or trimethoprim-sulfamethoxazole $10 / 50 \mathrm{mg} / \mathrm{kg} /$ day. ${ }^{3,39-41}$

Active antibiotics for nosocomial MRSA strains are usually limited to vancomycin, linezolid, daptomycin, ceftaroline, and tigecycline. There is a broader susceptibility in USA300 strains, which may be susceptibleto trimethoprimsulfamethoxazole, minocycline, and clindamycin. 
USA300 strains continue to dominate community-acquired forms of $S$. aureus infection, but are found with increasing frequency in hospital settings and are increasingly resistant to antibiotics, including tetracycline and clindamycin. ${ }^{3}$

For outpatient treatment of community-acquired MRSA infections, trimethoprim-sulfamethoxazole, minocycline, doxycycline, or clindamycin may be appropriate, depending on the severity of the illness and susceptibility of the

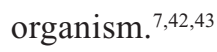

Telavancin, delbavancin, and oritavancin are vancomycin derivatives that kill $S$. aureus rapidly in a concentrationdependent manner in vitro. ${ }^{25}$ Carbapenems and cephalosporins have been developed against MRSA, and two cephalosporins, ceftobriprole and ceftaroline, have been shown to be clinically effective for treatment of skin and skin structure infections. Vancomycin derivatives and antiMRSA beta-lactams can only be administered intravenously. However, orally bioavailable oxazolidinones active against MRSA are in development. ${ }^{44-47}$

\section{Clinical indications}

In clinical trials, telavancin has been shown to be efficacious for the treatment of complicated skin and skin structure infections. ${ }^{26,27,48}$

\section{Phase II trials}

In 2004, Stryjewski et al conducted a randomized, doubleblind, controlled Phase II clinical trial in the US and South Africa, in which 167 patients aged older than 18 years and with a diagnosis of complicated skin or soft tissue infection caused by a suspected or confirmed Gram-positive organism, were randomized to receive either telavancin $7.5 \mathrm{mg} / \mathrm{kg}$ once daily intravenously $(\mathrm{n}=84)$ or standard therapy of vancomycin $1 \mathrm{~g}$ every 12 hours, nafcillin or oxacillin 2 g every six hours, or cloxacillin $0.5-1 \mathrm{~g}$ every six hours $(n=83)$. They were on treatment for 4-14 days. As Table 1 shows, for all treated patients, the cure rate was $79 \%$ and $80 \%$ for the telavancin and standard therapy groups, respectively. In the clinically evaluable population, $92 \%$ of the telavancin group and $96 \%$ of the standard therapy group were cured. In the microbiologically evaluable population, $93 \%$ of the telavancin group and $95 \%$ of the standard therapy group were cured. For the patients in whom $S$. aureus was isolated at baseline, cure was achieved at the test-of-cure evaluation in $80 \%$ of the telavancin group and $77 \%$ of the standard therapy group; in patients with MRSA at baseline, cure was achieved in $82 \%$ and $69 \%$ of the telavancin group and standard therapy group, respectively. At the test-of-cure evaluation, successful eradication of pathogens was seen in $80 \%$ and $82 \%$ of the telavancin group and standard therapy group, respectively. In patients infected with MRSA, test-of-cure evaluation was $84 \%$ for patients treated with telavancin and $74 \%$ for those treated with standard therapy. In all tests, the $P$ value was more than 0.05 , and no difference was statistically significant (see Table 1). ${ }^{26}$

Stryjewski et al also conducted a randomized, doubleblind, active control, parallel Phase II trial in two centers in the US and seven centers in South Africa in 2005. They recruited patients $>18$ years of age with complicated skin and soft tissue infection caused by suspected or confirmed Gram-positive pathogens. The objective of the study was to compare the safety and efficacy of telavancin $10 \mathrm{mg} / \mathrm{kg}$ once daily for the treatment of complicated skin and soft tissue infection with that of standard therapy (vancomycin $1 \mathrm{~g}$ every 12 hours or nafcillin or oxacillin $2 \mathrm{~g}$ /day or cloxacillin $0.5-1 \mathrm{~g}$ every six hours) for 4-14 days. They randomized a total of 195 patients (telavancin therapy group $=100$, standard therapy group $=95$; see Table 1 ). A cure rate was achieved at test-of-cure in $82 \%$ of the telavancin group and $85 \%$ of the standard therapy group $(P=0.37)$. In the clinically evaluable populations, $96 \%$ in the telavancin group and $94 \%$ in the standard therapy group $(P=0.53)$ were cured at test-ofcure evaluation. In the microbiologically evaluable population at test-of-cure, a cure was obtained in $97 \%$ in the telavancin group and $93 \%$ in the standard therapy group $(P=0.37)$. In microbiologically evaluable patients with $S$. aureus at baseline, $96 \%$ of those in the telavancin group and $90 \%$ of those in the standard therapy group were cured $(P=0.36)$. The same rates $(96 \%$ and $90 \%$ for telavancin and standard therapy, respectively, $P=0.42$ ) were observed for patients with MRSA. At test-of-cure, $S$. aureus eradication was higher in patients receiving telavancin $(92 \%$ versus $78 \%, P=0.07$, not statistically significant). In patients infected with MRSA, eradication rates were significantly higher in the telavancin group (92\% versus $68 \%, P=0.04$; see Table 1 ). In total, pathogen eradication was greater in patients receiving telavancin (94\% versus $83 \%, P=0.06$, not statistically significant; see Table 1$){ }^{27}$

\section{Phase III clinical trials}

In 2008, Stryjewski et al reported the results of the ATLAS (Assessment of TeLAvancin in Skin and skin structure infections) study. Two identical parallel, randomized, 
Table I Summary of the clinical results of telavancin or standard therapy for the treatment of complicated skin and soft tissue infections

\begin{tabular}{|c|c|c|c|c|c|c|c|c|c|}
\hline \multirow{2}{*}{$\frac{\text { Name of study }}{\text { Treatment }}$} & \multicolumn{3}{|c|}{ Phase II, FAST |a } & \multicolumn{3}{|c|}{ Phase II, FAST 2} & \multicolumn{3}{|c|}{ Phase III, ATLAS $^{\text {b }}$} \\
\hline & $\begin{array}{l}\text { Telavancin } \\
7.5 \mathrm{mg} / \mathrm{kg}\end{array}$ & $\begin{array}{l}\text { Standard } \\
\text { therapy }\end{array}$ & $P^{d}$ & $\begin{array}{l}\text { Telavancin } \\
10 \mathrm{mg} / \mathrm{kg}\end{array}$ & $\begin{array}{l}\text { Standard } \\
\text { therapy }\end{array}$ & $P$ & $\begin{array}{l}\text { Telavancin } \\
7.5 \mathrm{mg} / \mathrm{kg}\end{array}$ & $\begin{array}{l}\text { Vancomycin } \\
\text { I g// } 2 \text { hours }\end{array}$ & $\begin{array}{l}\text { Difference } \\
\text { in cure rate } \\
\text { ( } 95 \% \mathrm{Cl} \text { for } \\
\text { the difference) }\end{array}$ \\
\hline Number of patients & 84 & 83 & - & 100 & 95 & - & 928 & 939 & - \\
\hline Mean age of subjects & $44.6 \pm 13.9$ & $44.3 \pm 13.5$ & - & $44.7 \pm 13.7$ & $42.3 \pm 10.9$ & 0.18 & $48.8 \pm 16.6$ & $48.7 \pm 16.6$ & - \\
\hline $\begin{array}{l}\text { All treated } \\
\text { achieved cure }\end{array}$ & 66/84 (79\%) & $66 / 83(80 \%)$ & 0.53 & $82 / 100$ (82\%) & $81 / 95$ (85\%) & 0.37 & $\begin{array}{l}710 / 928 \\
(76.5 \%)\end{array}$ & $\begin{array}{l}697 / 939 \\
(74.2 \%)\end{array}$ & $2.3(-1.6,6.2)$ \\
\hline $\begin{array}{l}\text { Infected with } \\
\text { S. aureus, } \\
\text { achieved cure }\end{array}$ & $40 / 50(80 \%)$ & 40/52 (77\%) & 0.80 & $48 / 50$ (96\%) & $37 / 4 \mid(90 \%)$ & 0.36 & - & - & - \\
\hline $\begin{array}{l}\text { Infected with MRSA, } \\
\text { achieved cure }\end{array}$ & I8/22 (82\%) & $18 / 26(69 \%)$ & 1.00 & $25 / 26(96 \%)$ & $17 / 19$ (90\%) & 0.42 & $\begin{array}{l}252 / 278 \\
(90.6 \%)\end{array}$ & $\begin{array}{l}260 / 301 \\
(86.4 \%)\end{array}$ & $4.1(-1.1,9.3)$ \\
\hline $\begin{array}{l}\text { Clinically evaluable, } \\
\text { achieve cure }\end{array}$ & 66/72 (92\%) & $66 / 69$ (96\%) & 0.53 & 74/77 (96\%) & 72/77 (94\%) & 0.53 & $\begin{array}{l}658 / 745 \\
(88.3 \%)\end{array}$ & $\begin{array}{l}648 / 744 \\
(87.1 \%)\end{array}$ & I.2 (-2.I, 4.6) \\
\hline $\begin{array}{l}\text { Microbiologically } \\
\text { evaluable, achieved } \\
\text { cure }\end{array}$ & $52 / 56(93 \%)$ & $53 / 56(95 \%)$ & 0.79 & $62 / 64$ (97\%) & $53 / 77$ (93\%) & 0.37 & - & - & - \\
\hline $\begin{array}{l}\text { Microbiological } \\
\text { eradication of Gram } \\
\text { positive pathogens } \\
\text { at TOC }\end{array}$ & $44 / 56(80 \%)$ & $46 / 56(82 \%)$ & 0.53 & $46 / 50(92 \%)^{*}$ & $32 / 4 \mid(78 \%) *$ & 0.07 & $\begin{array}{l}473 / 527 \\
(89.8 \%)\end{array}$ & $\begin{array}{l}468 / 536 \\
(87.3 \%)\end{array}$ & $(-1.4,6.2)$ \\
\hline $\begin{array}{l}\text { Microbiological } \\
\text { eradication of MRSA, } \\
\text { at TOC }\end{array}$ & $16 / 19$ (84\%) & 14/19 (74\%) & 0.83 & $24 / 26$ (92\%) & $13 / 19$ (68\%) & 0.04 & $\begin{array}{l}250 / 278 \\
(89.9 \%)\end{array}$ & $\begin{array}{l}257 / 301 \\
(85.4 \%)\end{array}$ & $(-0.9,9.8)$ \\
\hline Adverse events & $47 / 84(56 \%)$ & $50 / 83(60 \%)$ & - & $56 / 100(56 \%)$ & $54 / 95$ (57\%) & 1.0 & $\begin{array}{l}735 / 928 \\
(79 \%)\end{array}$ & $\begin{array}{l}676 / 939 \\
(72 \%)\end{array}$ & - \\
\hline $\begin{array}{l}\text { Severe adverse } \\
\text { events }\end{array}$ & $3 / 84(4 \%)$ & 6/83 (7\%) & - & $6 / 100$ (6\%) & 4/95 (4\%) & - & $\begin{array}{l}69 / 928 \\
(7 \%)\end{array}$ & $42 / 939(4 \%)$ & - \\
\hline
\end{tabular}

Notes: aFAST: Name of study; ${ }^{\text {}}$ ATLAS: Assessment of TeLAvancin in Skin and skin structure infections; 'Standard therapy: vancomycin I g every 12 hours, nafcillin or oxacillin $2 \mathrm{~g} /$ day or cloxacillin $0.5-1 \mathrm{~g}$ every six hours; ${ }^{\mathrm{P}} \mathrm{P}$ values are from Bernard's unconditional test of superiority; indeterminate values were excluded from the calculations; ${ }^{e} 95 \% \mathrm{Cl}$ for the difference between the proportion of patients who were cured by telavancin and by vancomycin; *In this evaluation only Staphylococcus aureus pathogen was considered.

Abbreviations: MRSA, methicillin-resistant Staphylococcus aureus; TOC, test-of-cure; Cl, confidence intervals.

double-blind, active-controlled Phase III clinical studies with a prespecified pooled analysis design (studies 0017 and 0018) from January 2005 to June 2006 were carried out in 129 centers in 21 countries. They randomized men and nonpregnant women aged older than 18 years with a diagnosis of complicated skin and soft tissue infections that warranted more than seven days of parenteral antibacterial therapy. Patients received either intravenous telavancin $10 \mathrm{mg} / \mathrm{kg}$ every 24 hours or vancomycin $1 \mathrm{~g}$ every 12 hours for 4-14 days. The dose of telavancin was adjusted for patients with moderate to severe renal insufficiency, ie, $7.5 \mathrm{mg} / \mathrm{kg}$ every 24 hours for patients who had a creatinine clearance of $30-50 \mathrm{~mL} / \mathrm{min}$, and $10 \mathrm{mg} / \mathrm{kg}$ every 48 hours for creatinine clearance $<30 \mathrm{~mL} / \mathrm{min}$ (including patients on hemodialysis). No supplemental telavancin therapy was administered after dialysis. A total of 1867 patients were randomized and received at least one dose of study medication, with 928 receiving telavancin and 939 patients receiving vancomycin. More than two-thirds of patients were recruited for the study in the US. The $95 \%$ confidence intervals (CI) for the treatment difference between the two regimens from each study overlapped, enabling pooling of the data. In the clinically evaluable population, the clinical cure rates were $88.3 \%$ and $87.1 \%$ for the telavancinand vancomycin-treated groups, respectively $(95 \% \mathrm{CI}$ for the difference in cure rates, $-2.1,4.6)$. Of the clinically evaluable patients infected with MRSA at baseline, $90.6 \%$ of the patients in the telavancin group and $86.4 \%$ of the patients in the vancomycin group were cured $(95 \% \mathrm{CI}$ for the difference in cure rates, -1.1, 9.3). Among microbiologically evaluable patients at baseline, S. aureus were eradicated in $89.8 \%$ and $87.3 \%$ of the telavancin group and standard therapy group, respectively ( $95 \% \mathrm{CI}$ for the difference in cure rates, $-1.4,6.2$ ). Among 
microbiologically evaluable patients with MRSA isolates at baseline, eradication was $89.9 \%$ and $85.4 \%$ for telavancin and vancomycin treatment groups, respectively (95\% CI for the difference in cure rates, $-0.9,9.8$; see Table 1$)$. With regard to overall therapeutic response, patients were cured and pathogens were eradicated in $88.6 \%$ and $86.2 \%$ in the telavancin and vancomycin groups, respectively $(95 \% \mathrm{CI}$ for the difference in cure rates, $-1.6,6.4)$. Among clinically evaluable patients who had MRSA isolated at baseline $(n=579)$, the overall therapeutic response was higher in patients treated with telavancin than in patients treated with vancomycin $(89.9 \%$ versus $84.7 \%$; 95\% CI: $-0.3,10.5)$. The median duration of therapy was approximately one day shorter with telavancin than with vancomycin. ${ }^{48}$

In 2009, Wilson et al compared the results of telavancin versus vancomycin in patients with postsurgical complicated skin and soft tissue infection, particularly those infected with MRSA, who were treated in the ATLAS study. ${ }^{24}$ Of 1867 randomized patients, 194 had complicated skin and soft tissue infection related to a recent surgical procedure (all-treated population, telavancin $\mathrm{n}=101$, vancomycin $\mathrm{n}=93$ ). In $49 \%$ of these patients, $S$. aureus was isolated and identified as the pathogen, including $28 \%$ patients infected with MSSA and 22\% infected with MRSA. Trends favoring telavancin in clinical cure rates were observed in all analyzed populations. Those trends were strongest in the MRSA and MSSA subsets, but they did not reach statistical significance. Mean and median duration of treatment was 10 days in both groups. ${ }^{24}$

The ATLAS study contained one of the largest subsets of patients with complicated skin and soft tissue infection of any randomized, double-blind study to date, including those with documented MRSA infections. Not unexpectedly, this subset of patients with skin and soft tissue infection had a higher incidence of comorbid conditions compared with the overall ATLAS population. Nevertheless, telavancin proved at least as efficacious as vancomycin for treatment of patients with skin and soft tissue infections, including those infected with MRSA. The relatively small numbers of patients in the subgroups could be responsible for the lack of statistical differences. ${ }^{24}$

\section{Side effects}

The first Phase II clinical trial in 2005 reported adverse events in $56 \%$ and $60 \%$ of patients in the telavancin and standard therapy group, respectively. Adverse events possibly or probably related to therapy were reported for $32 \%$ of patients in the telavancin group and in $29 \%$ in the standard therapy group. Fewer patients in the telavancin group experienced severe adverse events (4\% versus $7 \%$ for the telavancin and standard therapy groups, respectively). Similar proportions of patients discontinued therapy because of an adverse event in both groups (6\% of the telavancin group and 5\% of the standard therapy group). The incidences of most adverse events were similar between the two groups. Three patients in the vancomycin group experienced red man syndrome, compared with none in the telavancin group. Maximum creatinine levels were $2.3 \mathrm{mg} /$ $\mathrm{dL}$ in the telavancin group, which occurred in two patients, and $2.5 \mathrm{mg} / \mathrm{dL}$ in the standard therapy group, which occurred in one patient. The remainder of the abnormal values ranged from $1.2 \mathrm{mg} / \mathrm{dL}$ to $1.8 \mathrm{mg} / \mathrm{dL}$. The increase in serum creatinine levels were documented as being reversible and did not lead to treatment discontinuation. Laboratory abnormalities included more elevated serum creatinine in the telavancin group than in the standard therapy group, and this was reversible. Microalbuminuria was found more commonly in patients with the telavancin group, but was not associated with abnormal serum creatinine levels. A mild decrease in platelet count (7\% versus $0 \%)$ and a 6.4 msec QT interval were observed more often in the telavancin group. ${ }^{26}$

The second Phase II clinical trial in 2006 reported adverse events in $56 \%$ and $57 \%$ in the patients who received telavancin and standard therapy, respectively. Among patients with adverse events, $73 \%$ of those in the telavancin group and $59 \%$ of those in the standard therapy group had events which were considered to be possibly or probably related to therapy $(P=0.16)$. Similar proportions of patients in both groups experienced severe adverse events $(6 \%$ and $4 \%$ for the telavancin and standard therapy groups, respectively) or were withdrawn from the study medication due to an adverse event (6\% in the telavancin group and $3 \%$ in the standard therapy group). Disseminated intravascular coagulation, atrial fibrillation, gastrointestinal bleeding, lobar pneumonia, subcutaneous abscess, wound infection, myositis, suicidal ideation, renal failure, ileostomy, hypotension, and wound hemorrhage were documented in the patients who received telavancin. The investigators also reported multiorgan failure, liver failure, bacteremia, sepsis, renal failure, atelectasis, lung infiltrations, and respiratory failure in the standard therapy group. Overall, mild and transient nausea, insomnia, headache, and taste alterations occurred more frequently in patients assigned to the telavancin group. Two patients on telavancin therapy had rashes of moderate severity and were withdrawn from the study. No case of red 
man syndrome was reported. Serum creatinine was increased in five patients in the telavancin group at the end of therapy. Maximum concentrations of serum creatinine were less than $1.8 \mathrm{mg} / \mathrm{dL}$ in all but one patient who had another predisposing medical problem and was withdrawn from the study on day 4. Hypokalemia was more common in the telavancin group. The minimum potassium value was $2.2 \mathrm{mEq} / \mathrm{L}$, and all other values at end of therapy ranged from 3.4 to $3.5 \mathrm{mEq} / \mathrm{L}$. The occurrence of hypomagnesemia and microalbuminuria was similar in both groups. Alteration in liver function tests and eosinophilia were less common among patients who received telavancin. According to an analysis of electrocardiographic data, a $12.5 \mathrm{msec}$ longer Fridericia corrected QT interval was seen in the telavancin group $(P \leq 0.0001)$. In addition, more corrected QT outliers were noted in the telavancin patients $(6 \%)$ compared with those on standard therapy $(1 \%)$. There were no cardiac adverse events reported to be associated with corrected QT prolongation. $^{27}$

In 2008, Strijewski et al documented adverse events in $79 \%$ and $72 \%$ of patients who received telavancin and vancomycin, respectively, in their Phase III trial. The incidence of serious adverse events was higher in the telavancin group than in the vancomycin group ( $7 \%$ versus $4 \%$, respectively). Slightly more patients discontinued telavancin therapy than vancomycin therapy ( $8 \%$ versus $6 \%$ ). Except for taste disturbance, mild nausea, vomiting, and foaming urine in the telavancin group $(33 \%, 27 \%, 14 \%$, and $13 \%$ for telavancin therapy versus $7 \%, 15 \%, 13 \%$, and $3 \%$ for the vancomycin group), adverse events were similar in type and severity between the groups. Taste disturbance was transient in the telavancin group, and was usually described as a metallic or soapy taste. Nausea and vomiting were mild. Individual serious adverse events and adverse events leading to discontinuation occurred in less than $1 \%$ in both treatment groups. Serum creatinine levels were increased by more than $1.5 \mathrm{mg} / \mathrm{dL}$ and more than $50 \%$ above the baseline level in $6 \%$ and $2 \%$ of patients in the telavancin and vancomycin groups, respectively. In all patients, serum creatinine concentrations returned to baseline values or were resolving at test-of-cure. One patient experienced temporary mild hearing loss with telavancin treatment. Renal dysfunction occurred in 3\% of patients in the telavancin group and in $1 \%$ of patients who received vancomycin, and serum creatinine concentrations returned to baseline values during the follow-up period. Less than $1 \%$ of the patients discontinued the study because of renal adverse events. An analysis of electrocardiographic data revealed that corrected QT interval outliers (QTc interval prolonged $>60 \mathrm{msec}$ ) occurred with similar frequency in both groups. One patient in the telavancin group and two patients in the vancomycin group had a corrected QT interval >500 msec during the study. No cardiac adverse events were associated with corrected QT interval prolongation. Other adverse events in both telavancin and vancomycin therapy groups included insomnia, constipation, diarrhea, dizziness, rash, infusion site pain, fatigue, chills, general pruritus, infusion site erythema, decreased appetite, anxiety, renal dysfunction, and abdominal pain. ${ }^{16,48}$

\section{Conclusion}

In summary, increasing resistance rates, acquisition in the community, and the emergence of more virulent strains have transformed MRSA into a major global health problem. In addition, intermediately vancomycin-susceptible $S$. aureus and even $S$. aureus fully resistant to vancomycin have been clinically documented.

Telavancin has a more potent bactericidal effect against MSSA and MRSA than do the beta-lactams, linezolid and vancomycin. In patients infected with MRSA, treatment with telavancin produced significantly higher bacterial eradication rates at test-of-cure than vancomycin $(92 \%$ versus $68 \%, P=0.04)$. Telavancin was four times more potent in vitro than vancomycin against the clinical strains of MRSA isolated during the study $\left(\mathrm{MIC}_{90}, 0.25 \mu \mathrm{g} / \mathrm{mL}\right.$ for telavancin versus $1.0 \mu \mathrm{g} / \mathrm{mL}$ for vancomycin). More importantly, telavancin achieved peak concentrations in serum more than 300-fold higher than the $\mathrm{MIC}_{90}$ for MRSA. Telavancin $10 \mathrm{mg} / \mathrm{kg}$ achieved higher clinical and microbiological response rates than telavancin $7.5 \mathrm{mg} / \mathrm{kg}$, which may at least in part be explained by its concentrationdependent bactericidal effects. Telavancin $10 \mathrm{mg} / \mathrm{kg}$ once daily is at least as effective as vancomycin twice daily for the treatment of the patients with complicated skin and soft tissue infections, and would be particularly useful for S. aureus strains exhibiting an increased MIC to vancomycin. Overall, the frequencies of adverse events were similar in the telavancin and vancomycin groups. Evaluation of serum creatinine levels at baseline and repeated after 48-72 hours of treatment is recommended. The advantages of using telavancin include once-daily dosing, shorter duration of treatment, and no requirement for monitoring of serum levels. The potential use of telavancin could be for recurrence of MRSA in complicated skin and soft tissue infections which have already been treated with vancomycin. 


\section{Disclosure}

The authors report no conflicts of interest in this work.

\section{References}

1. Deleo FR, Chambers HF. Reemergence of antibiotic-resistant Staphylococcus aureus in the genomics era. J Clin Invest. 2009;119(9): 2464-2474.

2. Klevens RM, Morrison MA, Nadle J, et al. Invasive methicillin-resistant Staphylococcus aureus infections in the United States. JAMA. 2007; 298(15):1763-1771.

3. Barlett JJ. Methicillin resistant Staphylococcus aureus infections. International AIDS Society USA topics in HIV Medicine. 11th Annual clinical update for the Ryan White HIV/AIDS Program clinicians. Top HIV Med. 2008;16(5):151-155.

4. Rubin RJ, Harrington LA, Poon A, et al. The economic impact of Staphylococcus aureus infection in New York City hospitals. Emerg Infect Dis. 1999;5(1):9-17.

5. Jevans MP, Coe AW, Parker MI. Methicillin resistance in staphylococci. Lancet. 1963;1(7287):904-907.

6. Cosgrove SE, Sakoulas G, Pevencevich EN, Schwaber MJ, Karchmer AW, Carmell Y. Comparison of mortality associated with methicillinresistant and methicillin-susceptible Staphylococcus aureus bacteremia: A meta analysis. Clin Infect Dis. 2003;36(1):53-59.

7. Kowalski TJ, Berbari EF, Osmon DR. Epidemiology, treatment and prevention of the community acquired methicillin resistant Staphylococcus aureus infections. Mayo Clin Proc. 2005;80(9): 1201-1208.

8. National Nosocomial Infection Surveillance system. National Nosocomial Infection: Surveillance system report data summary from January 1992 to June 2000. Am J Infect Control. 2000;28(6):429-448.

9. Boyle-Vavra S, Daum RS. Community-acquired methicillin-resistant Staphylococcus aureus: The role of Panton-Valentine leukocidin. Lab Invest. 2007;87(1):3-9.

10. Lina G, Piémont Y, Godail-Gamot F, et al. Involvement of PantonValentine leukocidin-producing Staphylococcus aureus in primary skin infections and pneumonia. Clin Infect Dis. 1999;29(5):1128-1132.

11. Farley JE. Epidemiology, clinical manifestations, and treatment options for skin and soft tissue infection caused by community acquired methicillin-resistant Staphylococcus aureus. J Am Acad Nurse Pract. 2008;20(2):85-92.

12. Miller LG, Perdreau-Remington F, Rieg G, et al. Necrotizing fasciitis caused by community-associated methicillin-resistant Staphylococcus aureus in Los Angeles. N Engl J Med. 2005;352(14): 1445-1453.

13. Lowy FD. Staphylococcus aureus infections. N Engl J Med. 1998; 339(8):520-532.

14. Otto M. Understanding the epidemic of community associated MRSA and finding a cure: Are we asking the right questions? Expert Rev Anti Infect Ther. 2009;7(2):141-143.

15. Klevens RM, Morrison MA, Fridkin SK, et al. Community-associated methicillin-resistant Staphylococcus aureus and healthcare risk factors. Emerg Infect Dis. 2006;12(12):1991-1993.

16. Leonard SN, Rybak MJ. Telavancin: An antimicrobial with a multifunctional mechanism of action for the treatment of serious gram positive infections. Pharmacotherapy. 2008;28(4):458-468.

17. Corey GR, Stryjewski ME, Weyenberg W, Yasothan U, Kirkpatrick P. Televancin. Nat Rev Drug Discov. 2009;8(12):929-930.

18. Judice JK, Pace JL. Semi-synthetic glycopeptide antibacterials. Bioorg Med Chem Lett. 2003;13(23):4165-4168.

19. Laohavaleeson S, Nicolau DP. Cost effectiveness of telavancin versus vancomycin for treatment of complicated skin and skin structure infections. Pharmacotherapy. 2008;28(12):1471-1482.

20. Laohavaleeson S, Kuti JL, Nicolau DP. Telavancin a novel lipoglycopeptide for serious gram positive infections. Expert Opin Investig Drugs. 2007;16(3):347-357.
21. Higgins DL, Chang R, Debabov DV, et al. Telavancin, a multifunctional lipoglycopeptide, disrupts both cell wall synthesis and cell membrane integrity in methicillin resistant Staphylococcus aureus. Antimicrob Agents Chemother. 2005;49(3):1127-1134.

22. Mendes RE, Moet GJ, Janechek MJ, Jones RN. In vitro activity of telavancin against a contemporary worldwide collection of Staphylococcus aureus isolates. Antimicrob Agents Chemother. 2010;54(6): 2704-2706.

23. Pace JL, Judice JK. Telavancin (Theravance). Curr Opin Investig Drugs. 2005;6(2):216-225.

24. Wilson SE, O'Riordan W, Hopkins A, Friedland HD, Barriere SL, Kitt MM; ATLAS Investigators. Telavancin versus vancomycin for the treatment of complicated skin and skin structure infections associated with surgical procedures. Am J Surg. 2009;197(6):791-796.

25. Gusky MT, Tsuji BT. A comparative review of the lipoglycopeptides: Oritavancin, delbavancin and telavancin. Pharmacotherapy. 2010; 30(1):80-94.

26. Stryjewski ME, O'Riordan WD, Lau WK, et al. Telavancin versus standard therapy for treatment of complicated skin and soft tissue infections due to gram-positive bacteria. Clin Infect Dis. 2005;40(11): 1601-1607.

27. Stryjewski ME, Chu VH, O'Riordan WD, et al. Telavancin versus standard therapy for the treatment of complicated skin and skin structure infections caused by Gram positive bacteria: FAST 2 Study. Antimicrob Agents Chemother. 2006;3:826-867.

28. Scheinfeld N. A comparison of available and investigational antibiotics for complicated skin and skin infections and treatment resistant Staphylococcus aureus and enterococcus. J Drugs Dermatol. 2007;6(1): 97-103.

29. Shaw JP, Seroogy J, Kaniga K, Higgins DL, Kitt M, Barriere S. Pharmacokinetics, serum inhibitory and bactericidal activity, and safety of telavancin in healthy subjects. Antimicrob Agents Chemother. 2005; 49(1):195-201.

30. Wong SL, Barriere SL, Kitt MM, Goldberg MR. Multiple-dose pharmacokinetics of intravenous telavancin in healthy male and female subjects. J Antimicrob Chemother. 2008;62(4):780-783.

31. Duchin K, Shaw J, Spencer E, Seroogy J, Barriere S, Wilbraham D. Single dose pharmacokinetics (PK) of telavancin in healthy elderly subjects. Poster P1028 presented at the 14th European Congress of Clinical Microbiology and Infectious Disease. Prague, Czech Republic, May 1-4, 2004.

32. Patel JH, Churchwell MD, Seroogy JD, Barriere SL, Grio M, Mueller B. Telavancin and hydroxy propyl-beta-cyclodextrin clearance during continuous renal replacement therapy: An in vitro study. Int J Artif Organs. 2009;32(10):745-751.

33. Goldberg MR, Wong SL, Shaw JP, Kitt MM, Barriere SL. Lack of effect of moderate hepatic impairment on the pharmacokinetics of telavancin. Pharmacotherapy. 2010;30(1):35-42.

34. Goldberg MR, Wong SL, Shaw JP, Kitt MM, Barriere SL. Single-dose pharmacokinetics and tolerability of telavancin in elderly men and women. Pharmacotherapy. 2010;30(8):806-811.

35. Sun HK, Duchin K, Nightingale CH, Shaw JP, Seroogy J, Nicolau DP. Tissue penetration of telavancin after intravenous administration in healthy subjects. Antimicrob Agents Chemother. 2006;50(2):788-790.

36. Lodise TP Jr, Gotfried M, Barriere S, Drusano GL. Telavancin penetration into human epithelial lining fluid determined by population pharmacokinetic modeling and Monte Carlo simulation. Antimicrob Agents Chemother. 2008;52(7):2300-2304.

37. Gotfried MH, Shaw JP, Benton BM, et al. Intrapulmonary distribution of intravenous telavancin in healthy subjects and effect of pulmonary surfactant on in vitro activities of telavancin and other antibiotics. Antimicrob Agents Chemother. 2008;52(1):92-97.

38. Dunbar LM, Tang DM, Manausa RM. A review of telavancin in the treatment of complicated skin and skin structure infections (cSSSI). Ther Clin Risk Manage. 2008;4(1):235-244.

39. Dancer SJ. The effect of antibiotics on methicillin resistant Staphylococcus aureus. J Antimicrob Chemother. 2008;61(2):246-253. 
40. Wong G, Hindler JF, Ward KW, Bruckner DA. Increased vancomycin MICs for Staphylococcus aureus clinical isolates from a university hospital during a 5 year period. J Clin Microbiol. 2006;44(11): 3883-3886.

41. Tenover FC, Moellering RC Jr. The rationale for revising the Clinical and Laboratory Standards Institute vancomycin minimal inhibitory concentration interpretive criteria for Staphylococcus aureus. Clin Infect Dis. 2007;44(9):1208-1215.

42. Llera JL, Levy RC. Treatment of cutaneous abscess: A double-blind clinical study. Ann Emerg Med. 1985;14(1):15-19.

43. Khatib R, Johnson LB, Sharma M, Fakih MG, Ganga R, Riederer K. Persistent Staphylococcus aureus bacteremia: Incidence and outcome trends over time. Scand J Infect Dis. 2009;41(1):4-9.

44. Chambers HF, DeLeo FR. Waves of resistance: Staphylococcus aureus in the antibiotic era. Nat Rev Microb. 2009;7(9):629-641.
45. Parish D, Scheinfeld N. Ceftaroline fosamil, a cephalosporin derivative for the potential treatment of MRSA infection. Curr Opin Investig Drugs. 2008;9(2):201-209.

46. Anderson SD, Gums JG. Ceftobiprole: An extended-spectrum anti-methicillin-resistant Staphylococcus aureus cephalosporin. Ann Pharmacother. 2008;42(6):806-816.

47. Shaw KJ, Poppe S, Schaadt R, et al. In vitro activity of TR-700, the antibacterial moiety of the prodrug TR-701, against linezolid-resistant strains. Antimicrob Agents Chemother. 2008;52(12):4442-4447.

48. Strijewski ME, Graham DR, Wilson SE, et al. Telavancin versus vancomycin for the treatment of complicated skin and skin structure infections caused by gram positive organism. Clin Infect Dis. 2008;46(11): 1683-1693.

\section{Publish your work in this journal}

Infection and Drug Resistance is an international, peer-reviewed openaccess journal that focuses on the optimal treatment of infection (bacterial, fungal and viral) and the development and institution of preventive strategies to minimize the development and spread of resistance. The journal is specifically concerned with the epidemiology of antibiotic

\section{Dovepress}

resistance and the mechanisms of resistance development and diffusion in both hospitals and the community. The manuscript management system is completely online and includes a very quick and fair peerreview system, which is all easy to use. Visit http://www.dovepress. com/testimonials.php to read real quotes from published authors.

Submit your manuscript here: http://www.dovepress.com/infection-and-drug-resistance-journal 